\title{
Mindful Ambassador Program: An Acceptable and Feasible Universal Intervention for College Students
}

\author{
Gulden Esat ${ }^{1}$, Syed Rizvi ${ }^{1}$, Caroline Mousa ${ }^{1}$, Kimberly D. Smoots ${ }^{1}$, Ester Shaw ${ }^{2}$, Chase R. Phillip ${ }^{2}$, Meliza \\ Vasquez ${ }^{2}$, Arifa Habib ${ }^{1}$, Elizabeth Vu$^{2}$ and Bradley H Smith ${ }^{1 *}$ \\ ${ }^{1}$ Department of Psychological, Health and Learning Sciences, University of Houston, USA \\ ${ }^{2}$ Department of Psychology, University of Houston, USA
}

Submission: April 09,2021; Published: April 22,2021

*Corresponding author: Bradley H. Smith, Department of Psychological, Health, and Learning Sciences, University of Houston, Texas, USA

Keywords: Mindful ambassador; Stress; Depression; Anxiety; Well-being, College student

\section{Mindful Ambassador Program}

The majority of college students report significant distress. For example, a recent survey found that $82 \%$ struggled with anxiety, 63\% suffered with depression, and 60\% had difficulty coping with stress in a healthy way [1]. Although college student distress is caused by multifaceted contextual and socioeconomic variables that require systemic changes; mindfulness interventions stand out as a promising way to reduce distress. Several studies have found significant effects of mindfulness interventions that are similar in magnitude to individual therapy for improving distress, depression, anxiety, and well-being [2]. Considering the pervasiveness of the distress among college students, universal mindfulness interventions (i.e., mindfulness training for all college students) could have sweeping effects on college campuses. With this in mind, the authors developed the Mindful Ambassador Program (MAP) to foster the well-being of college students in a feasible and costeffective way that can engage large numbers of students.

A unique aspect of MAP is that it specifically targets the developmental needs of a diverse population of college students. Accordingly, MAP is designed to cultivate self-awareness with respect to thoughts, emotions, and values pertinent to young adulthood; improve self-regulation skills to cope with stressors commonly experienced by college students; and promote systemic awareness to foster meaningful civic engagement.
These targets of intervention by the MAP program are currently under investigation.

The present brief report describes the acceptability, feasibility, and effectiveness of MAP for reducing college student distress, which is a critical first step when developing universal interventions.

The workability of MAP was iteratively developed over three years of investigation that followed the principles of action research [3]. Acceptability and feasibility were established along the course of two pilot and three effectiveness studies, engaging a total of over 500 students. Based on student participation rates, the best way to deliver MAP was via a set of brief (i.e., 10 to 15 minute), interactive mindfulness lessons provided by peer facilitators (i.e., Mindful Ambassadors) during scheduled class time. This programming resulted in over $90 \%$ participation in MAP, with at least $80 \%$ of the diverse student population at our university giving positive ratings of the relevance, practicality, and helpfulness of the lessons [4]. The strategy of delivering the mindfulness lessons in class time brought about an absolute advantage over the other models, such as voluntary participation in virtual MAP lessons, which had less then 15 to $20 \%$ participation.

The implementation fidelity procedures of the classroom based MAP provided evidence that the intervention was 
feasible to implement with high fidelity by unpaid volunteers who were recruited, trained, and supervised by a research lab in partnership with a student organization [4]. Furthermore, there is preliminary evidence on the long-term effectiveness of the MAP. For instance, the distress levels of students were kept at a stable level during the semester they received MAP and at the five-month follow-up. On the other hand, the control group reported significant increases in distress toward the end of the following semester [4].

In sum, MAP, a universal mindfulness program delivered by peer-volunteers during class time, is a promising approach to address the high levels of distress among college students. The negative association of distress with academic achievement [5] is critically important because failed classes lead to drop out [6], eventually saddling many students with high debt but no degree. College administrators should seriously consider adopting universal, classroom-based programs like MAP, as our research group has found that individually selfscheduled approaches to mindfulness are unlikely to get sufficient participation for positive results.

\section{References}

1. Martinez A. Nguyen S (2020) The Impact of Covid-19 on College Student Well-Being. American College Health Association, Healthy Minds Student Survey.

2. Dawson AF, Brown WW, Anderson J, Datta B, Donald JN, et al. (2019) Mindfulness-Based Interventions for university students: a systematic review and meta-analysis of randomized controlled trials. Applied Psychology: Health and Well-Being 12(2): 384-410.

3. Cargo M, Mercer SL (2008) The value and challenges of participatory research: strengthening its practice. Annu Rev Public Health 29: 325350.

4. Esat G, Smith BH, Rizvi S, Kim H (2021) Developing universal mindfulness interventions: An acceptable, feasible, and effective example.

5. Hysenbegasi A, Hass SL, Rowland CR (2005) The impact of depression on the academic productivity of university students. J Ment Health Policy Econ 8(3): 145-151.

6. Allen J, Robbins S (2010) Effects of interest-major congruence, motivation, and academic performance on timely degree attainment. J Couns Psychol 7(1): 23-25.

Your next submission with Juniper Publishers
will reach you the below assets
- Quality Editorial service
- Swift Peer Review
- Reprints availability
- E-prints Service
- Manuscript Podcast for convenient understanding
- Global attainment for your research
- Manuscript accessibility in different formats
( Pdf, E-pub, Full Text, Audio)
- Unceasing customer service
Track the below URL for one-step submission
https://juniperpublishers.com/online-submission.php

